\title{
Current-to-current converter for scientific underwater cable networks
}

\section{$\operatorname{AUTHOR}(\mathrm{S}):$}

Asakawa, Kenichi; Kojima, Junichi; Muramatsu, Jun; Takada, Tatsuo; Kawaguchi, Katsuyoshi; Mikada, Hitoshi

\section{CITATION:}

Asakawa, Kenichi ...[et al]. Current-to-current converter for scientific underwater cable networks. IEEE JOURNAL OF OCEANIC ENGINEERING 2007, 32(3): 584-592

\section{ISSUE DATE:}

2007-07

URL:

http://hdl.handle.net/2433/84533

\section{RIGHT:}

C) 2007 IEEE. Personal use of this material is permitted. However, permission to reprint/republish this material for advertising or promotional purposes or for creating new collective works for resale or redistribution to servers or lists, or to reuse any copyrighted component of this work in other works must be obtained from the IEEE. 


\title{
Current-to-Current Converter for Scientific Underwater Cable Networks
}

\author{
Kenichi Asakawa, Member, IEEE, Junichi Kojima, Member, IEEE, Jun Muramatsu, Tatsuo Takada, \\ Katsuyoshi Kawaguchi, Member, IEEE, and Hitoshi Mikada, Senior Member, IEEE
}

\begin{abstract}
A new current-to-current converter, which is a key device to branch a constant direct current (dc) into two constant des, was proposed [K. Asakawa et al., Proc. OCEANS, pp. 1868-1873, 2003]. It has been verified, through computer simulations and experiments using prototypes, to have good conversion efficiency and stable operation. Because the basic circuit is simple, high reliability is expected. The current-to-current converter is a key device to realize a constant current (CC) power-feeding system for scientific underwater cable networks having mesh topology, which is necessary to enhance robustness against cable breakdowns and to deploy sensors in 2-D and efficiently over a vast research area.
\end{abstract}

Index Terms-Constant current (CC), current-to-current converter, scientific underwater cable network.

\section{INTRODUCTION}

$\mathbf{S}_{\mathrm{b}}$ CIENTIFIC underwater cable networks are anticipated to be the most promising means to achieve continuous realtime, long-term, and 3-D underwater observation covering a wide region, which is necessary to elucidate the nature of oceans and the earth.

Accelerated by the recent evolution of the submarine optical cable technology and related technologies such as computers, Internet, electronics, etc., several ambitious scientific underwater cable network projects have been proposed and initiated. The United States and Canada have commenced the joint project called the Northeast Pacific Time-Series Undersea Networked Experiment (NEPTUNE), ${ }^{1}$ which will emplace a scientific underwater cable network in the northeastern Pacific Ocean. In Monterey Bay, CA, and in the ocean around Victoria

Manuscript received December 12, 2005; revised December 6, 2006; accepted February 12, 2007. Most of the material presented in this paper is based on presentations at the IEEE 2003 OCEANS Conference and the MTS/IEEE 2004 TECHNO-OCEAN Conference.

Associate Editor: R. C. Spindel.

K. Asakawa and K. Kawaguchi are with the Japan Agency for Marine-Earth Science and Technology (JAMSTEC), Yokosuka 237-0061, Japan (e-mail: asakawa@jamstec.go.jp).

J. Kojima is with the KDDI R\&D Laboratories, Saitama 356-8502, Japan.

J. Muramatsu is with the Sonar Systems Department, Radio Application Division, NEC Corporation, Tokyo 183-8501, Japan.

T. Takada is with the Toritsu Tsushin Kogyo Corporation, Tokyo 141-0031, Japan.

H. Mikada is with the Department of Civil and Earth Resources Engineering, Kyoto University, Kyoto 615-8540, Japan.

Color versions of one or more of the figures in this paper are available online at http://ieeexplore.iee.org.

Digital Object Identifier 10.1109/JOE.2007.905024

${ }^{1}$ University of Washington, Seattle (available at http://www.neptune.washington.edu/) and University of Victoria, Victoria, BC, Canada (available at http://www.neptunecanada.ca/) and Vancouver, Canada, respectively, the Monterey Accelerated Research System (MARS) ${ }^{2}$ and Victoria Experimental Network Under the Sea (VENUS) ${ }^{3}$ projects are also underway. In Europe, the European Seafloor Observatory Network (ESONET $)^{4}$ consortium has proposed ten scientific cable networks in the submarine terrain around Europe. These networks will be used for multidisciplinary investigations including those of geophysics, oceanography, biology, chemistry, biochemistry, and fisheries.

In Japan, eight scientific underwater cables have been constructed and they currently operate [1]. Because Japan is located near plate boundaries where catastrophic earthquakes and tsunamis occur periodically, seismology has a higher priority in view of disaster mitigation.

Considering the previously described situations, the IEEE Oceanic Engineering Society Japan Chapter has organized a technical committee to promote a technical feasibility study [2], [3] of scientific underwater cable networks. The committee was established in February 2002 [9].

The proposed scientific underwater cable network [2], [3] is named advanced real-time earth monitoring network in the area (ARENA). Although the main mission of ARENA is seismic observation, it is intended to be used multidisciplinarily.

Fig. 1 shows that ARENA has a mesh topology, which facilitates deployment of sensors over a vast observation area. It has multiple landing stations. Various sensors are connected to cables through underwater hub units. The mesh topology is also effective to increase robustness against cable shunt faults. Because the cable network is connected to multiple landing stations, each observation node has plural routes to landing stations. For that reason, even if one route is broken, it will be linkable to another landing station through another route and observations can continue. This feature is necessary, especially as a countermeasure against cable faults caused by earthquakes because it is a rare chance to observe aftershocks and it is very important for disaster mitigation and seismic studies.

In ARENA, underwater telecommunication cables will be used as trunk cables because they have superior reliability. Their configuration is simple and their cost is moderate. All related technologies and tools for construction and repair work are available. Because only one electric conductor exists, as shown in Fig. 2, in the underwater optical telecommunication cable, the return current flows in the seawater.

\footnotetext{
${ }^{2}$ Monterey Bay Aquarium Research Institute (MBARI), Moss Landing, CA; available at http://www.mbari.org/mars/

${ }^{3}$ University of Victoria, Victoria, BC, Canada; available at http://www.venus uvic.ca/

${ }^{4}$ University of Aberdeen, Newburgh, Aberdeenshire, U.K.; available at http:// www.abdn.ac.uk/ecosystem/esonet/
} 


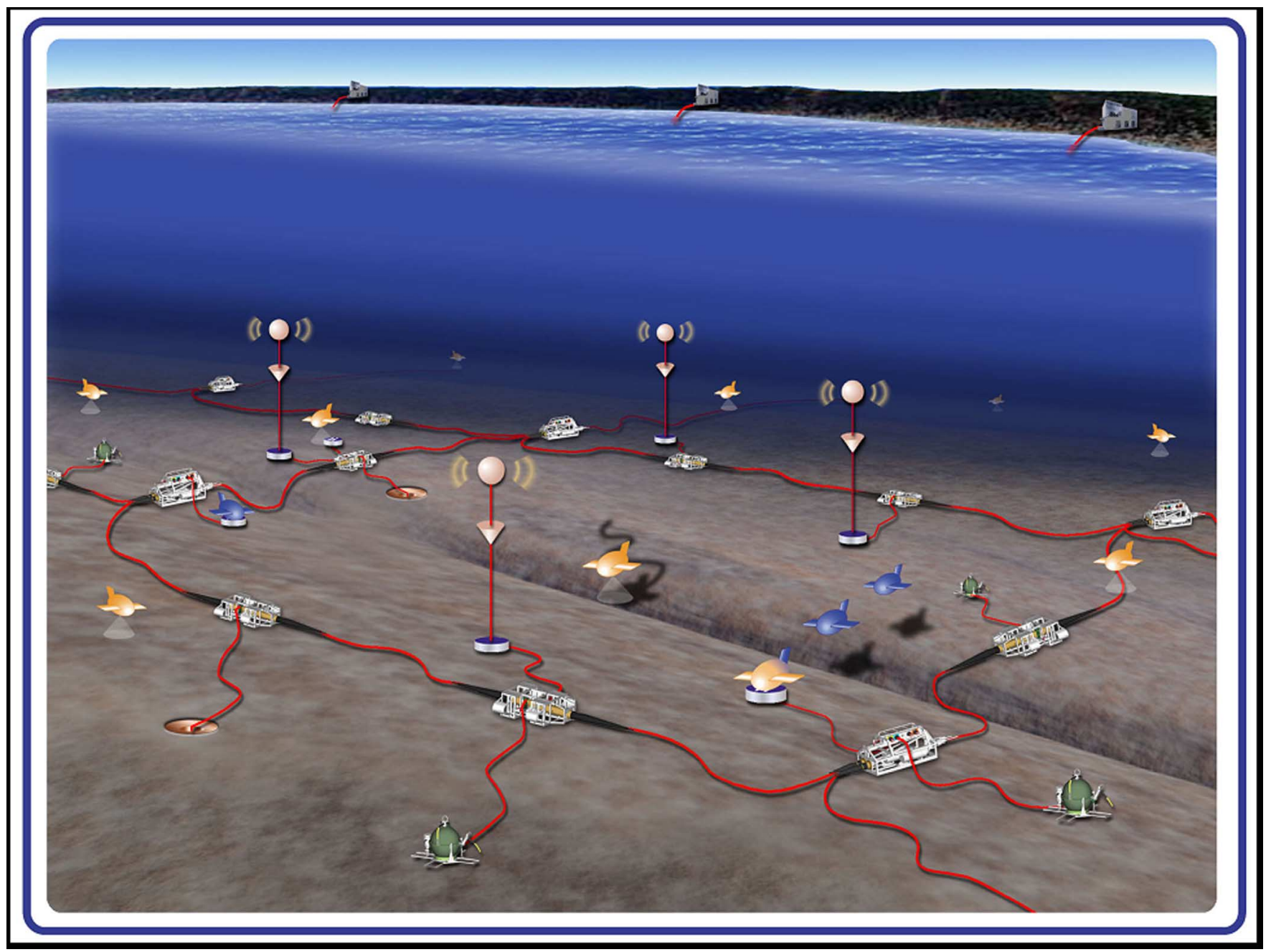

Fig. 1. Image of ARENA.

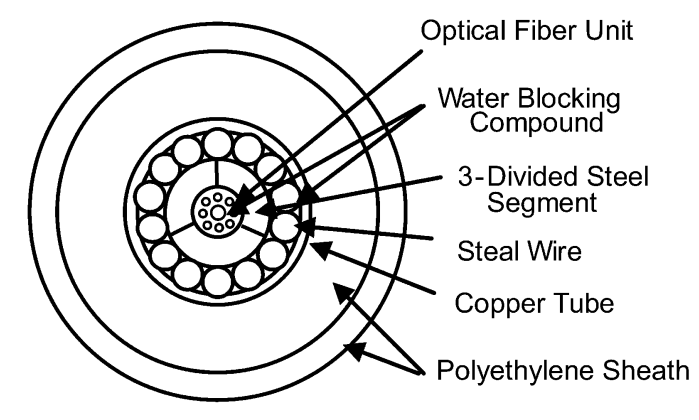

Fig. 2. Typical cross-sectional view of lightweight optical telecommunication cables.

For conventional underwater telecommunication cable systems, a constant current (CC) power-feeding system is used, because it has the following advantages.

1) It is robust against cable shunt faults. Because electric power is usually supplied from both ends of the cable, even if the cable is shunted to seawater at one point, electric power can be supplied continuously to the entire cable from both ends. Only the electrical potential distribution of the cable changes.
2) In case of a cable shunt fault, the fault point can be localized by measuring the direct current (dc) resistance between the power-feeding line and the sea earth.

3) It is easy to isolate underwater electric circuits in repeaters electrically against seawater because there is no sea earth brought into repeaters.

In case of shunt faults where current is flowing in from seawater to the conductor, electric corrosion will not occur and we can continue to supply power. However, in case of shunt faults where current is flowing out from a fault point to seawater, the exposed conductor will corrode and the shunt impedance will increase. In such a case, one means to continue to supply power is to reverse the polarity of the current. Repeaters and current-to-current converters should be bipolar. Adding a rectifying circuit at the input stage, repeaters and current-to-current converters are easily rendered bipolar.

In the feasibility study, the three following power-feeding systems were compared:

1) CC power-feeding system;

2) constant voltage (CV) power-feeding system;

3) hybrid system that includes a CC power-feeding system and a $\mathrm{CV}$ power-feeding system.

Advantages for a CC power-feeding system for telecommunication cable systems mentioned previously are applicable 


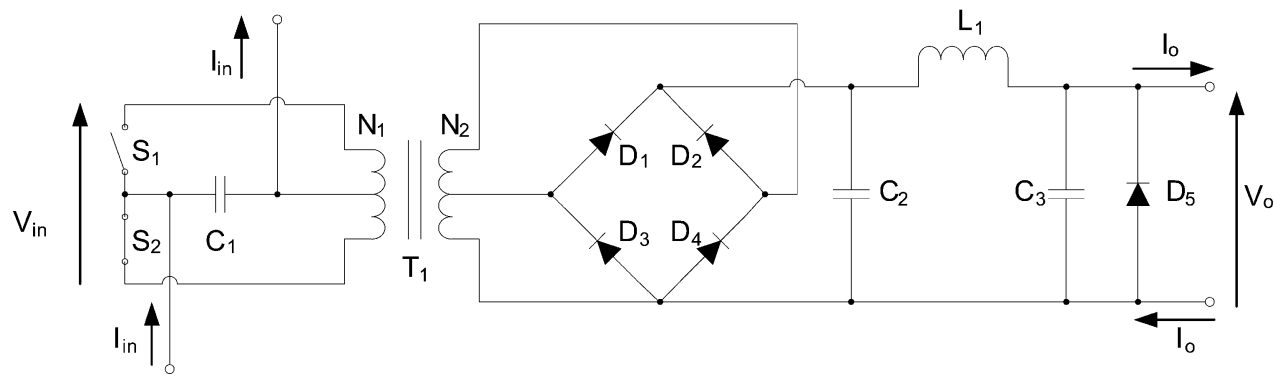

Fig. 3. Basic circuit diagram of the current-to-current converter.

to scientific cables, except for item 3 ), because a node or a branching unit will necessitate a sea earth in the housing. However, there was no device to divide a CC into two CCs. Such a device was necessary to supply a CC to cable networks having mesh topology. On the other hand, a CV power-feeding system presents the advantage of easily dividing a $\mathrm{CV}$ power supply line into plural lines [4]. It is also suitable to provide large electric power because it is easy to divide electric power. The NEPTUNE system adopted a CV power-feeding system [5], [6], which is now being developed. However, a new method should be developed to find cable shunt faults and to remove faulted sections to continue operation when shunt faults occur. Power supply systems in underwater devices must be more sophisticated than those for CC power-feeding systems, because electric power for underwater devices should be taken from higher dc voltage of several kilovolts.

The authors have proposed a new current-to-current converter [7], which is a key device to divide a CC into two CCs. It enables construction of a mesh-like cable network with a CC powerfeeding system. Results of experiments using two prototypes and results of computer simulations are presented in this paper. These results show promising characteristics of the proposed current-to-current converter.

\section{BASIC CIRCUIT}

Fig. 3 shows a basic circuit diagram of the converter. The input dc current $I_{\text {in }}$ is switched with switching devices such as metal-oxide-semiconductor field-effect transistors (MOSFETs) and is converted to the alternating current (ac) and input to a transformer. The output current of the transformer is rectified to produce another output dc $I_{O}$. The ratio between the input and the output current $I_{i} / I_{o}$ is almost equal to $N_{1} / N_{2}$ where $N_{1}$ and $N_{2}$ are the winding numbers of the transformers. The magnitude of the output current is almost proportional to the magnitude of the input current. In other words, if the input current is constant, the output current will also be constant; the current-to-current converter divides a $\mathrm{CC}$ into two $\mathrm{CCs}$. In the design of the prototypes, we made $N_{1}$ and $N_{2}$ equal.

Because the basic circuit is very simple and no feedback loop exists, high reliability and high conversion efficiency are expected.

Overvoltage and overcurrent sensors are put in the input stage, but they are not shown in Fig. 3. The overvoltage sensor is used to protect the converter in case of high impedance fault in the cable. To increase the output voltage and the power,

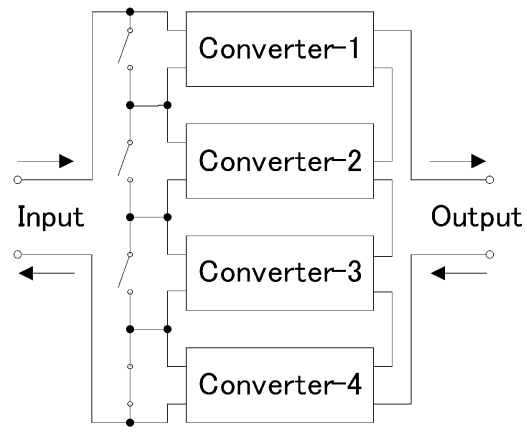

Fig. 4. Connection of plural converters.

inputs and outputs of plural converters are connected in series, as depicted in Fig. 4. Because current-to-current converters will be placed on the seafloor, and because it is not easy to recover and repair them when they fail, higher reliability and robustness are required. In Fig. 4, converter-4 is shown as a standby; its input is shunted in normal operation. In this case, the output current flows through the diode $D_{5}$ in the converter-4. The input of the failed converter will be shunted and converter- 4 will be activated if one of the other converters breaks. This redundancy increases the reliability of the current-to-current converter.

\section{COMPARISON BETWEEN EXPERIMENTS AND COMPUTER SIMULATION}

\section{A. Simulation Model}

To deepen our understanding of the converter, we conducted computer simulations and compared those results with experimental results. The simulation was done using PSpice. Fig. 5 shows the basic circuit used in the simulation.

A linear core model was used for the transformer $T_{1}$ because the magnetic flux density in the experiment was much lower than that of the saturation level. In the linear model, a transformer was represented by two inductances, a coupling coefficient, and resistances of windings. Resistances $R_{1}$ and $R_{2}$ in the primary of the transformer represent the loss in the ferrite core and switching loss of field-effect transistors (FETs).

\section{B. Waveform}

Fig. 6 shows a comparison between observed waveforms and simulation results. The upper two waveforms in the figure show 


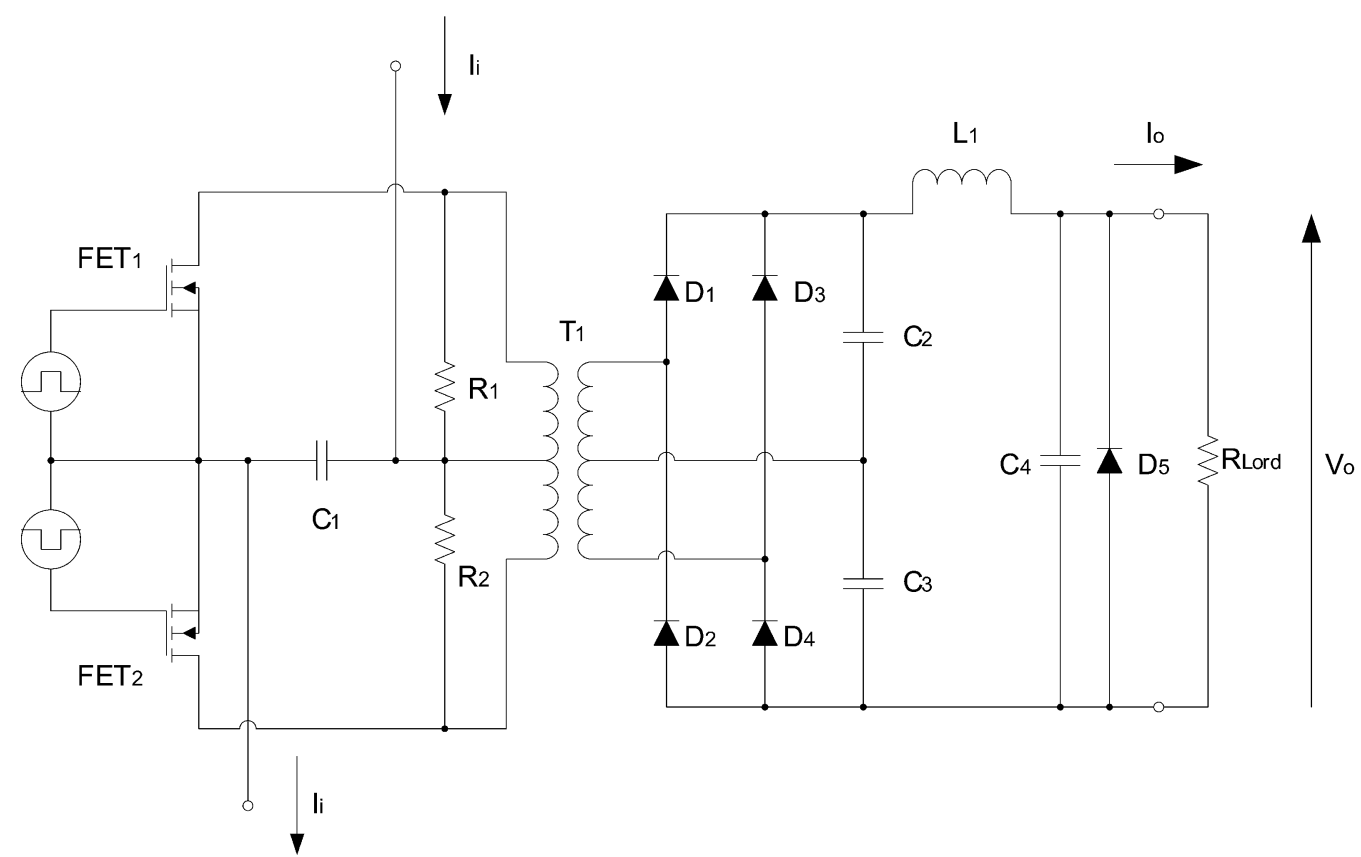

Fig. 5. Basic circuit diagram for the simulation.

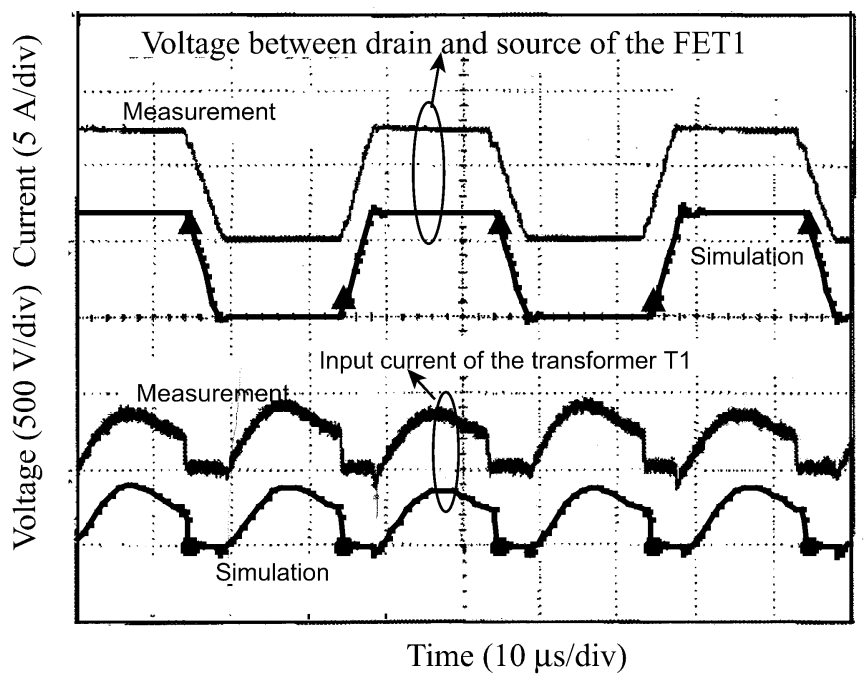

Fig. 6. Comparison of observed waveforms and simulation results.

the source-drain voltage of the $\mathrm{FET}_{1}$; the lower two waveforms show the current flowing into the transformer.

The coupling coefficient of the transformer was selected as 0.992 so that the calculated current waveform coincided with measured waveforms. This coupling coefficient shows good agreement with the measured value of 0.994 .

The simulated waveform coincides well with the measured waveforms, which proves the validity of the simulation.

\section{Output Characteristics}

We have produced three converters and compared their output characteristics. Fig. 7 shows that the output currents are almost constant regardless of the output voltage; they can be considered as CC sources. The equivalent slope resistance is about

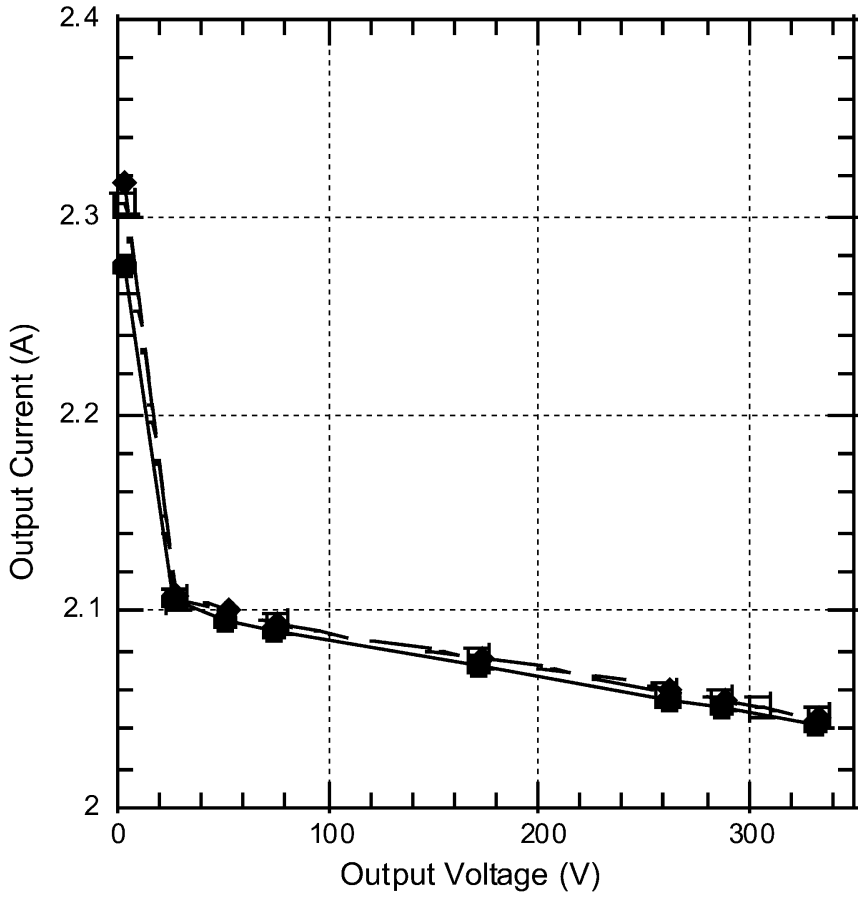

Fig. 7. Output characteristics of the first prototype.

$5.6 \mathrm{k} \Omega$. This slope resistance corresponds to the output resistance. The output current should be the same when plural converters are connected in series. Because the converter has finite slope resistance, the output current range has some allowance. This allowance makes it possible to connect plural converters in series. The moderate slope resistance is suitable for the series connection, which renders a very high slope resistance undesirable. The output characteristics of these converters are quite similar, which also facilitates the series connection. 


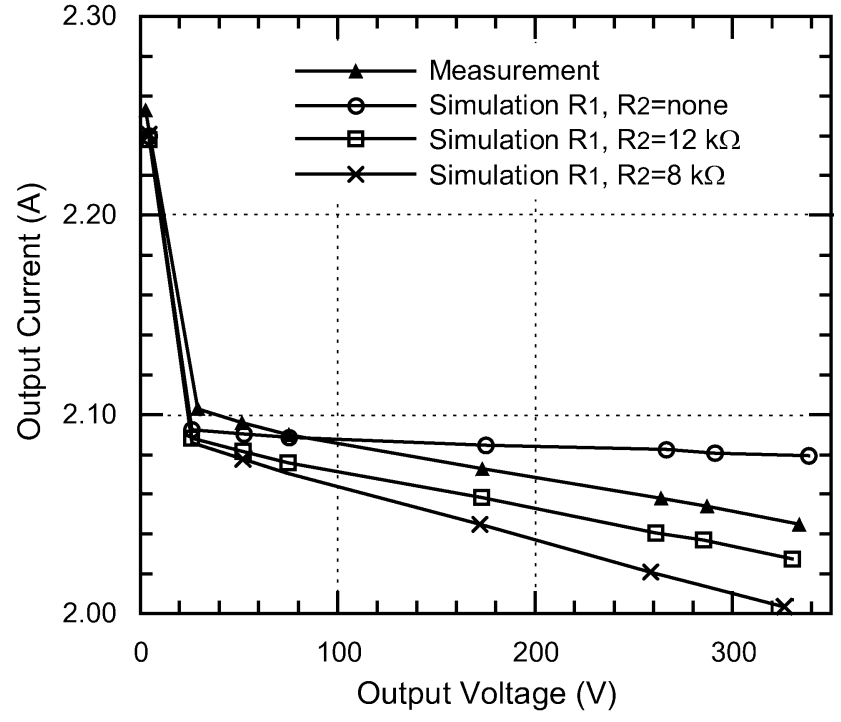

Fig. 8. Influence of deviation of $R_{1}$ and $R_{2}$ against the output characteristics.

Increase of output current is apparent at regions of lower than $20 \mathrm{~V}$ output. It is caused by the intrinsic body diode of MOSFETs. When one MOSFET is switched off, the body diode within the other MOSFET is activated because of the transformer's inductance; the current continues flowing through the circuit of the body diode, transformer, and capacitor $C_{1}$. When the output load is heavier and the output voltage is higher, the energy of this current will be absorbed rapidly by the output load and the current will decay. However, if the output voltage is lower and the output load is lighter, the current decay is rather slow. This residual current flowing through the body diode increases the output current in the lower output voltage region.

Fig. 8 shows the simulated and measured output characteristics, where $R_{1}$ and $R_{2}$ are changed as parameters. The output characteristics with $R_{1}$ and $R_{2}$ of $12 \mathrm{k} \Omega$ coincide well with the measured characteristics; also, the deviation of resistance affects the output characteristics. The output resistance of the converter is approximated as $\left(R_{1}+R_{2}\right) / 2=6 \mathrm{k} \Omega$, which is almost equal to the measured slope resistance of $5.6 \mathrm{k} \Omega$.

Fig. 9 shows the output characteristics when the on-resistance of FETs $\left(R_{\mathrm{on}}\right)$ is changed. Because the converter is driven with CC, the deviation of on-resistance of FET does not affect the output characteristic. The deviation of winding resistance of the transformer does not affect the output characteristics for the same reason. However, these resistances degrade the converter efficiency.

Fig. 10 shows output characteristics of the converter when the coupling coefficient of the transformer was changed as a parameter. This figure shows that the deviation of coupling coefficient influences the output characteristic in the lower output voltage region when it is lower than 0.99. Because the measured coupling coefficient of 0.994 is greater than 0.99 , practically speaking, its deviation has little influence on the output characteristic.

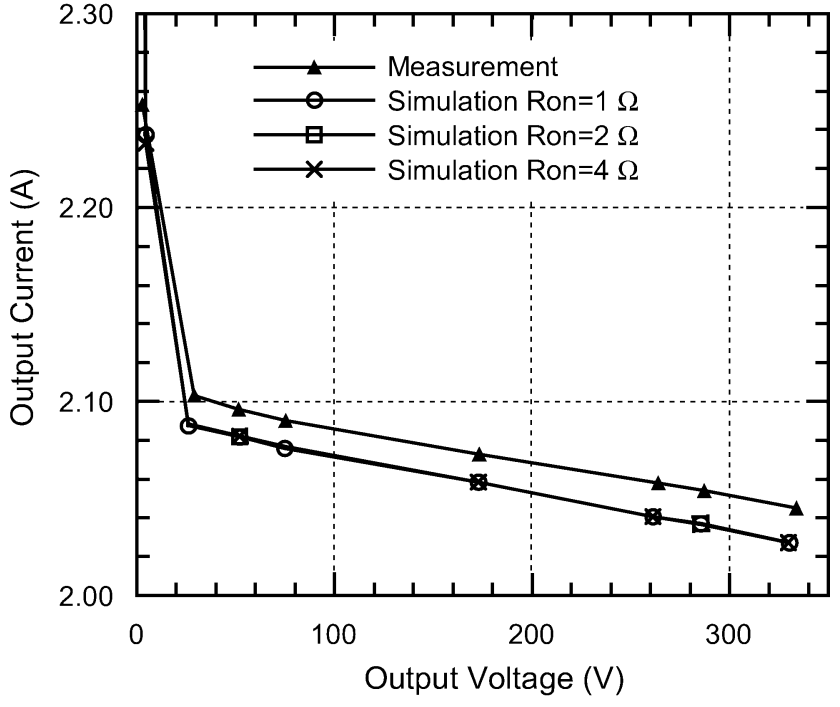

Fig. 9. Influence of on-resistance ( $\left.R_{\text {on }}\right)$ of FETs against output characteristics.

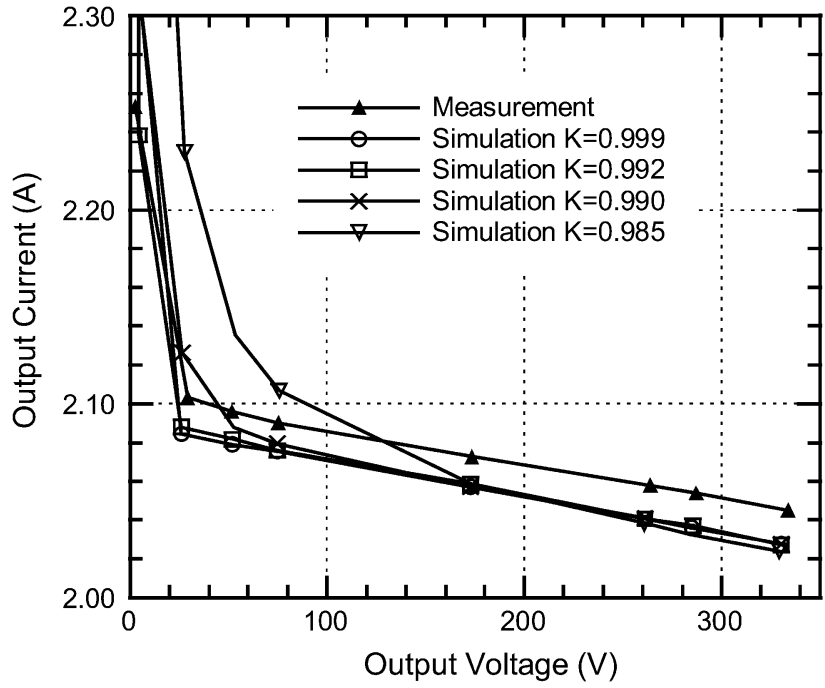

Fig. 10. Influence of the coupling coefficient of the transformer against the output characteristics.

\section{Efficiency}

The converter efficiency is shown in Fig. 11. Neither the power consumed by the drive circuit nor the control circuit is included in this calculation. The simulation and the measurement show good agreement in the higher voltage region, where efficiency of about $95 \%$ is obtained. Little difference exists in the lower voltage region.

The calculated breakdown of the loss in the higher voltage region is shown in Table I. Because the loss of the core can be estimated as about $3 \mathrm{~W}$, the switching loss of FET, which is estimated to be about $17.8 \mathrm{~W}$, is dominant.

\section{E. Temperature Characteristics}

Fig. 12 shows the measured temperature dependence of the output characteristics. The output current and slope resistance are temperature dependent, which is considered to be mainly the result of the transformer's temperature dependence. However, because differences between output characteristics of the three 


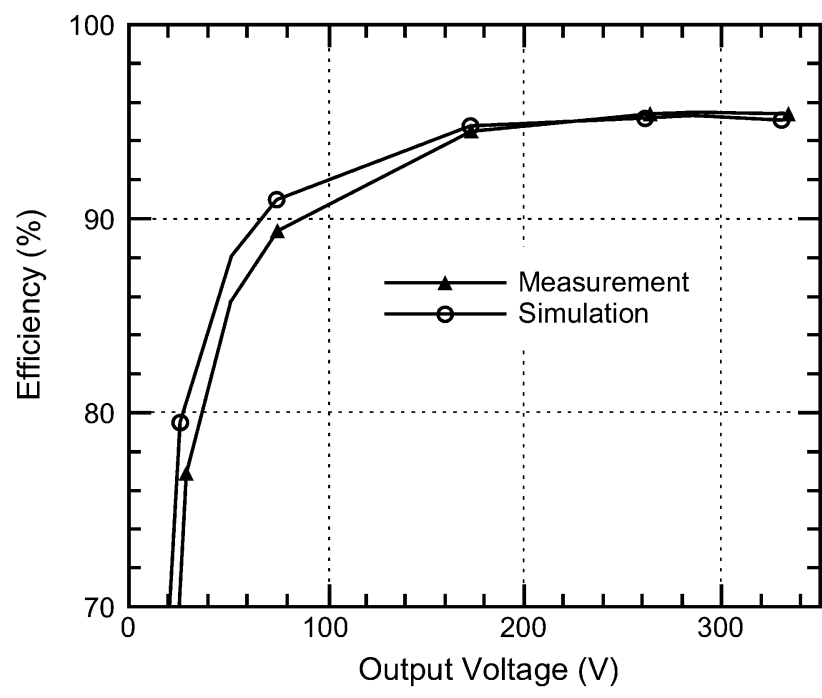

Fig. 11. Efficiency of the first prototype.

TABLE I

DETAILS OF THE LOSS (OUTPUT VOLTAGE: $330 \mathrm{~V}$ ) $R_{1}$ AND $R_{2}$, RESPECTIVELY, REPRESENT THE LOSS IN THE CORE AND THE SWITCHING LOSS OF FETS

\begin{tabular}{c|c}
\hline Item & Loss \\
\hline On-resistance of FET & $6.3 \mathrm{~W}$ \\
\hline Power loss of $R_{1}$ and $R_{2}$ & $20.7 \mathrm{~W}$ \\
\hline Diodes $D_{1}, D_{2}, D_{3}$ and $D_{4}$ & $3.2 \mathrm{~W}$ \\
\hline Resistance of winding wire & $1.3 \mathrm{~W}$ \\
\hline Other losses & $3.6 \mathrm{~W}$ \\
\hline Total & $35.1 \mathrm{~W}$ \\
\hline
\end{tabular}

converters are small for all temperatures, they can be connected in series at these temperatures.

\section{COMPACT PROTOTYPE}

We have produced a compact second prototype [8] which can be mounted in a branching unit (BU, depicted in Fig. 13) of underwater telecommunication cable systems. We then evaluated its performance. The $\mathrm{BU}$ can be deployed to and recovered from 6000-m depth.

\section{A. Basic Specifications}

Table II shows the basic specifications of the second prototype. The specifications for voltage and size are applicable to the entire system. Four converters are connected in series to increase the power output. Fig. 14 shows a photograph of the whole system.

The basic circuit of those converters is the same as that of the first prototype.

\section{B. Electrical Characteristics}

Fig. 15 shows output characteristics of the whole system in which four converters are connected in series. It can be reconfirmed that the output can be regarded as a CC source. The slope

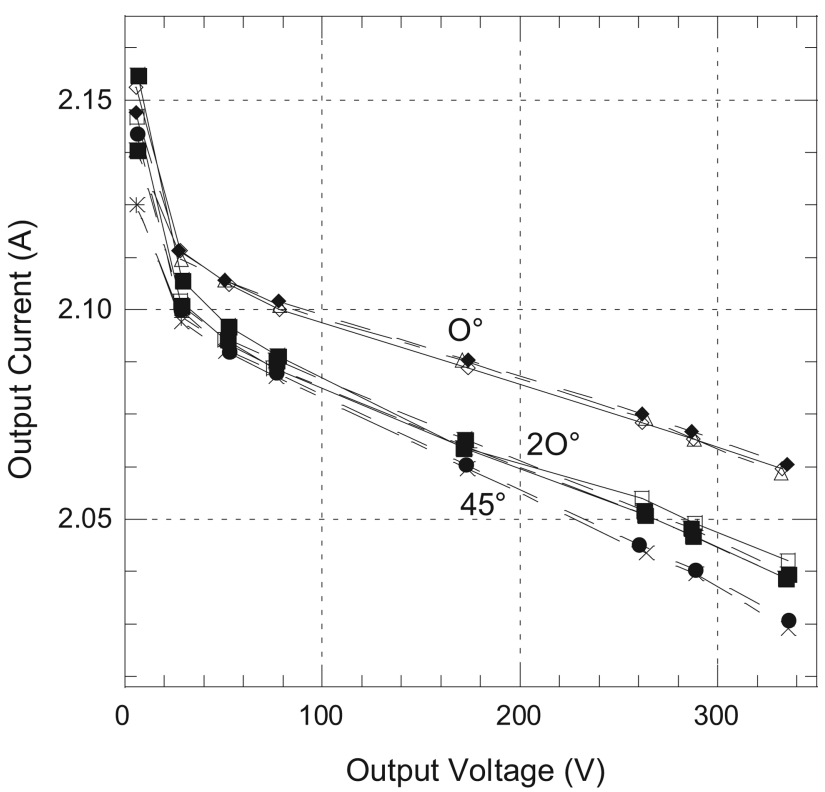

Fig. 12. Temperature dependency of the output characteristics.

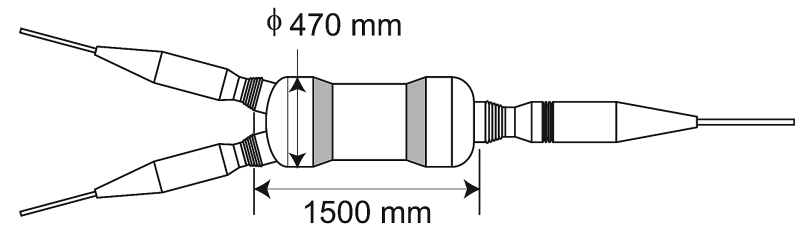

Fig. 13. Typical appearance of BU for optical telecommunication cable systems.

TABLE II

Basic Specifications of the SeCond PRototype

\begin{tabular}{|l|l|}
\hline Items & Specifications \\
\hline Max. Input Current & $1.4 \mathrm{~A}$ \\
\hline Max. Output Voltage & $600 \mathrm{~V}$ \\
\hline Max. Output Current & $1.4 \mathrm{~A}$ \\
\hline Number of & 4 \\
\hline Sonverters & \\
\hline Efficiency & Higher than $90 \%$ \\
\hline Size & $375 \mathrm{~mm}(\mathrm{~L}) \times 200 \mathrm{~mm}(\mathrm{H}) \times$ \\
& $200 \mathrm{~mm}(\mathrm{~W})$ \\
\hline
\end{tabular}

resistance is about $11.5 \mathrm{k} \Omega$ in the output voltage range higher than $100 \mathrm{~V}$. The output resistance of a converter is about $2.9 \mathrm{k} \Omega$, which is one-quarter of the slope resistance of the whole system. It is because four converters are connected in series. We think the difference between the slope resistance of the first prototype and that of the second prototype is mainly attributable to 


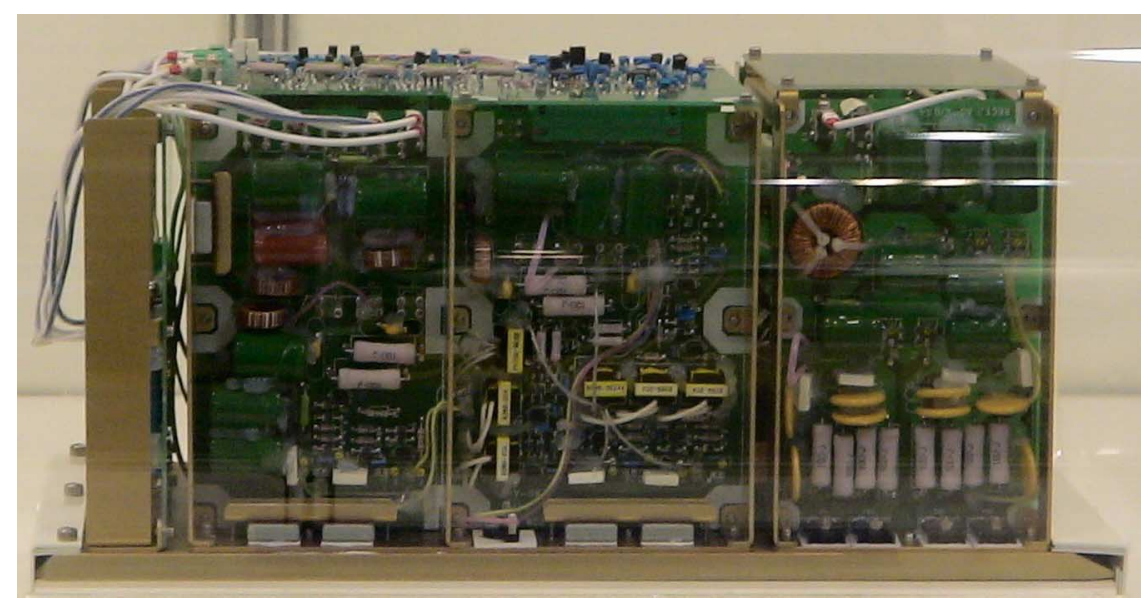

Fig. 14. Photograph of the second prototype.

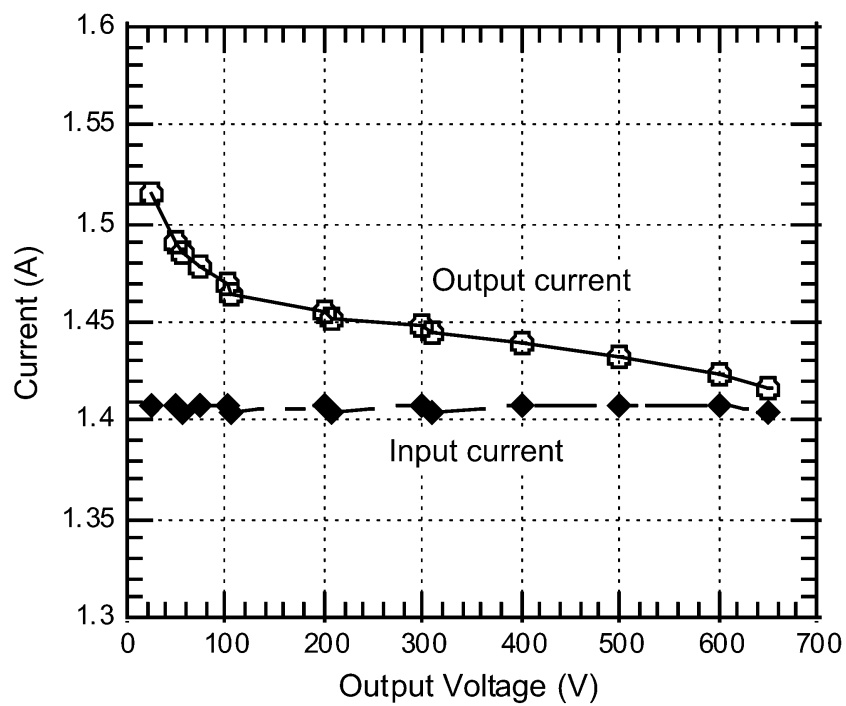

Fig. 15. Output characteristics of the second prototype.

the difference between the transformers. We used smaller transformers for the second prototype to reduce the size, which increased losses in the core and decreased the slope resistance.

The converter efficiency is described in Fig. 16. Although the power consumed by the controller is not included in the calculation of the efficiency, high efficiency of about $95 \%$ in the higher output range is realized.

All the results described previously concur with those obtained with the first prototype.

\section{Heat Dissipation}

Heat dissipation is an important issue because the converters are mounted in a watertight housing, the heat dissipation characteristics of which are poor, especially in the air. It also affects the long-term reliability.

Fig. 17 shows results of the experiment of temperature rise with the maximum load. The converters were housed in a rectangular housing, which had almost equivalent heat dissipation characteristics to those of BUs. Fans are not used, thereby increasing the long-term reliability. Seven temperature sensors were attached to each part of the current-to-current converter.

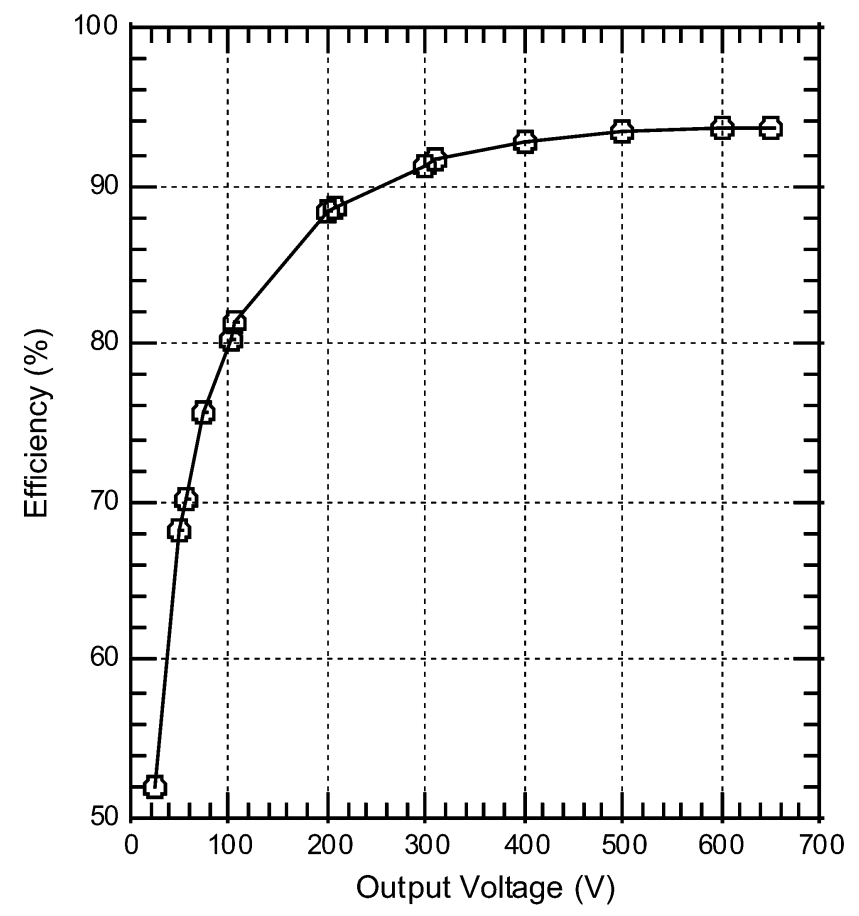

Fig. 16. Efficiency of the second prototype.

Fig. 17 shows that the temperature became stable after about $7 \mathrm{~h}$. Because the temperature rise is less than $23^{\circ} \mathrm{C}$, its effect on long-term reliability is inferred to be negligible. The locations at which the temperature rise was highest were the transformer surface and the top of the circuit board. Because the FETs and diodes are installed directly on the base plate, which has good thermal conductance, the temperature rises of these devices are less than that of the transformer.

\section{CONClusion}

The CC power-feeding system presents many advantages for scientific underwater cable networks. The authors have proposed a new current-to-current converter, which is a key device to realize mesh-like cable networks with a CC power-feeding system. Because the basic circuit is simple and no feedback loop exists, it is easy to obtain higher reliability. 


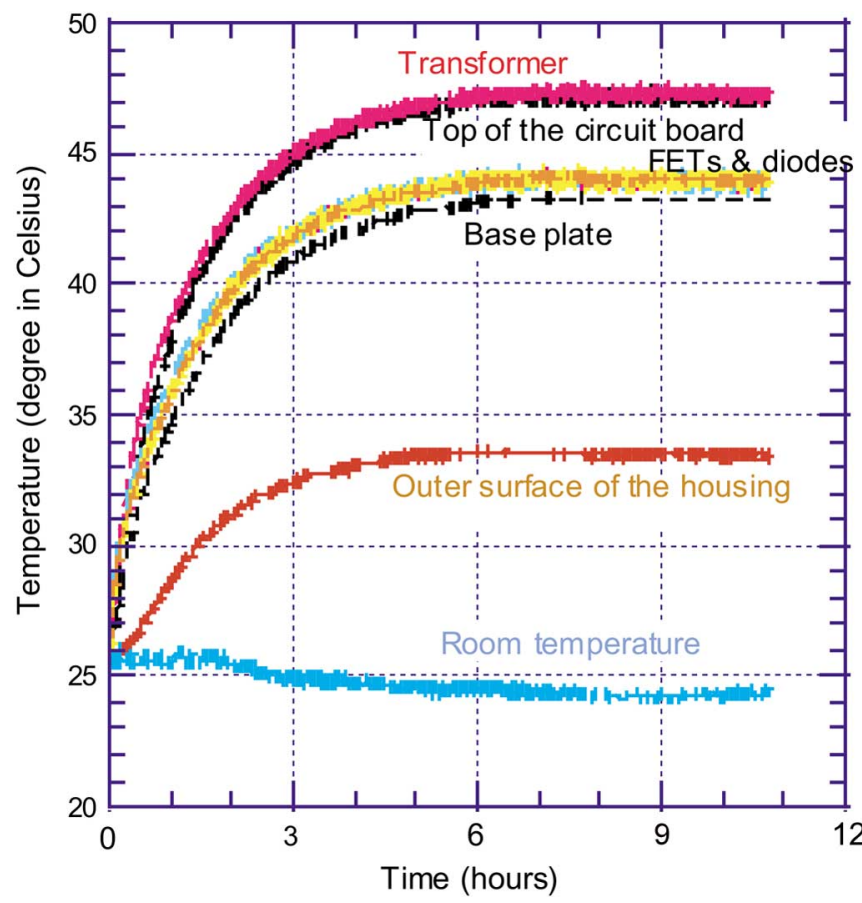

Fig. 17. Results of the experiment of temperature rise with the maximum load.

Two prototypes of the current-to-current converter were developed and evaluated.

Experiments using the first prototype confirmed the following:

1) the proposed current-to-current converter has good characteristics;

2) because the output resistance is sufficiently high, it can be regarded as a current source;

3) the conversion efficiency is higher than $95 \%$ in the higher voltage region;

4) the output characteristics of the three converters are sufficiently compatible that they can be connected in series to increase the output power.

The results of the simulation agree well with the experimental results, which proves the validity of the simulation. The simulation showed the following:

1) the loss in the ferrite core and the switching loss of FETs have dominant influence on output characteristics;

2) on the other hand, on-resistance of FET and the coupling coefficient exert little influence on output characteristics.

A temperature rise test was conducted using the second prototype. In that test, the current-to-current converter was placed in a rectangular housing that had thermal properties that were almost equivalent to those of BUs. Results confirmed that the temperature rise was sufficiently low that its effects on long-term reliability were negligible.

These results show that the proposed current-to-current converter has promising features. It will provide great benefits for the design and construction of scientific underwater cable networks.

\section{REFERENCES}

[1] K. Asakawa, H. Mikada, K. Kawaguchi, R. Iwase, K. Hirata, T. Goto, K. Mitsuzawa, H. Matsumoto, T. Watanabe, and K. Suyehiro, "Envisioned network system for future underwater observations," in Proc. TECHNO-OCEAN Conf., 2002, CD-ROM.

[2] K. Asakawa, J. Muramatsu, M. Aoyagi, K. Sasaki, and K. Kawaguchi, "Feasibility study on real-time seafloor globe monitoring cable network-Power feeding system," in Proc. 2002 Int. Symp. Underwater Technol., 2002, pp. 116-122.

[3] Y. Shirasaki, T. Nishida, M. Yoshida, Y. Horiuchi, J. Muramatsu, M. Tamaya, K. Kawaguchi, and K. Asakawa, "Proposal of next-generation real-time seafloor globe monitoring cable-network," in Proc. OCEANS Conf., 2002, pp. 1688-1694.

[4] J. Kojima, B. How, K. Asakawa, and H. Kirkham, "Power systems for ocean regional cabled observatories," in Proc. OCEANS/TECHNOOCEAN Conf., 2004, pp. 2176-2181.

[5] B. M. Howe, H. Kirkham, and V. Vorpérian, "Power system considerations for undersea observatories," IEEE J. Ocean. Eng., vol. 27, no. 2, pp. 267-274, Apr. 2002.

[6] K. Schneider, C.-C. Liu, and B. Howe, "Topology error identification for the NEPTUNE power system," IEEE J. Ocean. Eng., vol. 20, no. 3, pp. 1224-1232, Jun. 2005.

[7] K. Asakawa, J. Kojima, J. Muramatsu, and T. Takada, "Novel current to current converter for mesh-like scientific underwater cable network-Concept and preliminary test result," Proc. OCEANS Conf., pp. 1868-1873, 2003.

[8] K. Asakawa, J. Muramatsu, J. Kojima, T. Takada, K. Kawaguchi, and H. Mikada, "Current-to-current converter for mesh-like scientific underwater cable networks-A compact-sized prototype," Proc. OCEANS/TECHNO-OCEAN Conf., pp. 2182-2186, 2004.

[9] Technical Committee on Globe Monitoring Cable Network, "Scientific submarine cable network," Tech. White Paper, Jan. 2003 [Online]. Available: http://homepage.mac.com/ieee_oes_japan/ ARENA/ARENA-E.html

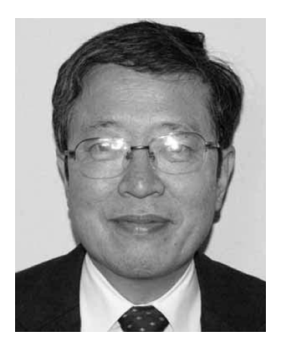

Kenichi Asakawa (M'96) received the B.E., M.S., and Dr. Eng. degrees in electronic engineering from Tokyo Institute of Technology, Tokyo, Japan, in 1974, 1976, and 1979, respectively.

$\mathrm{He}$ joined KDD Research and Development Laboratories in 1979, where he was engaged in developments of remotely operated vehicles (ROVs), autonomous underwater vehicles (AUVs), and other technologies related to construction and maintenance of underwater telecommunication cables. From 1995 to 1999 , he was engaged with VENUS project, the object of which was to reuse decommissioned underwater coaxial telecommunication cable for scientific observation. He moved to KDD-Submarine Cable Systems in 2000, where he was in charge of development of underwater equipment for underwater optical telecommunication cables. In 2002, he moved to the Japan Marine Science and Technology Center (now Japan Agency for Marine-Earth Science and Technology, Yokosuka, Japan). Since then, he has been involved in development and maintenance of scientific cabled observation systems and its application.

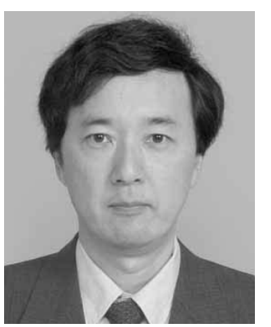

Junichi Kojima (M'04) received the B.E. and M.E. degrees in electrical engineering from Tokyo Institute of Technology, Tokyo, Japan, in 1979 and 1981, respectively.

He joined KDD (now KDDI, Tokyo, Japan) in 1981, and since then he has been engaged in research and development in the construction and maintenance of underwater telecommunication cables. His research interests include AUVs, acoustic telemetry system for AUVs, and cable fault location systems. 


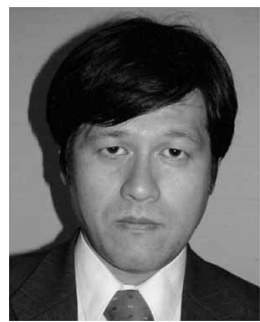

Jun Muramatsu received the B.E. degree in ocean engineering from Tokai University, Shizuoka, Japan, in 1985 .

He joined NEC Corporation, Tokyo, Japan, in 1985, where he is currently an Assistant Manager of Sonar Systems Department, Radio Application Division. From 1985 to 1997, he had been involved in the development of defense sonobuoy systems. Since 1997, he has been involved in the development of cabled earth observation systems and acoustic data communications systems including data transmission systems between sensors on ocean bottom and moored buoys. Currently, he is involved in research of oceanic sensor networks that utilize acoustic data transmission systems and underwater cables.

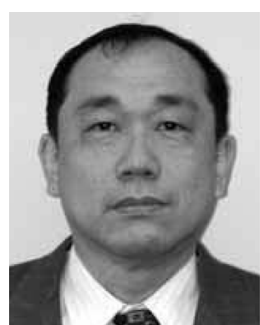

Tatuo Takada received the B.E. degree from Tamagawa University, Tokyo, Japan, in 1979.

He joined Tohritsu Corporation, Tokyo, Japan, in 1979. He was assigned to Electric Power Development Section, where he designed high-voltage power supplies. He was involved in the development of power supplies for long-distance submarine cables from 2001 to 2005 . He moved to Integran Inc., Tokyo, Japan, in 2006. Since then, he has been engaged in designing of military power supplies.

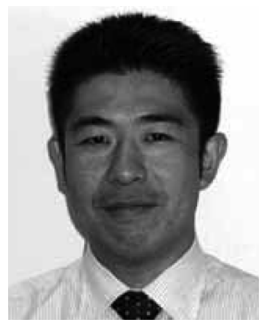

Katsuyoshi Kawaguchi (M'96) was born in Tokyo, Japan, in 1964. He received the B.E. degree in ocean engineering and the M.S. and Ph.D. degrees in marine science from Tokai University, Japan, in 1987, 1989, and 1993, respectively.

From 1993 to 1995, he was a Lecturer at the Department of Marine Mineral Resources, Tokai University. Between 1995 and 1996, he was a Postdoctoral Researcher at the Mechanical Engineering Department, University of Hawaii, Honolulu. From 1996 to 1998 , he was a Postdoctoral Researcher at the Deep Sea Research Department, Japan Marine Science and Technology Center, Japan. Since 1998, he has been a Researcher at Japan Marine Science and Technology Center (present name: Japan Agency for Marine-Earth Science and Technology). His research background is underwater robotics (hardware and software design, and control). Currently, he is involved in developing the geoscientific real-time seafloor observation system and its applications.

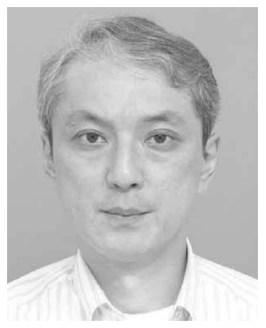

Hitoshi Mikada (M'02-SM'06) received the B.Sc., M.Sc., and Ph.D. degrees in geophysics from the University of Tokyo, Tokyo, Japan, in 1981, 1983, and 1994, respectively.

Currently, he is an Associate Professor at Kyoto University, Kyoto, Japan. He joined Schlumberger as an R\&D Engineer in 1983 and moved to Etudes et Productions Schlumberger, France, as a Senior Project Engineer in geophysics. Then, in 1991, he was a Research Associate at the Earthquake Research Institute, University of Tokyo, continuing his geophysical studies. He moved back to Schlumberger as a Section Manager for the Interpretation Methodology Development in 1997. Then, he was a Scientist at the Japan Marine Science and Technology Center from 1999 to 2004, working on the development of long-term seafloor monitoring systems for earthquake and tsunami disaster mitigation. Since 2004, he has been working at the Department of Civil and Earth Resources Engineering, Kyoto University in the crustal engineering section. His main interests include research in seismic scattering theories, seismic wave propagation in attenuating and anisotropic media, deep-water seismic surveys, geophysical logging, the investigation of tsunami/earthquake generation mechanisms, and the development of sensors and systems for geophysical measurements/observations. 